\title{
A MUCH MISREAD PROPOSITION FROM PROCLUS' ELEMENTS OF THEOLOGY (PROP. 28)
}

Jan Opsomer (University of Leuven)

Proposition 28 from Proclus' Elements of theology is consistently cited as saying that every producing cause first brings about effects that are like it and then effects that are unlike it. This is a theorem to which Proclus is indeed committed, but I argue that it is not what Proclus is claiming here. At this stage of his general argument, he merely argues that every cause produces things that are like it, without saying anything about other products than the immediate ones. The standard interpretation of proposition 28 is therefore wrong. This becomes clear if one pays close attention to the argumentative structure of the Elements of theology and to the proof given for proposition 28 .

In the translation by E.R. Dodds, ${ }^{1}$ proposition 28 reads as follows: 'Every producing cause brings into existence things like to itself before the unlike.' This is indeed what

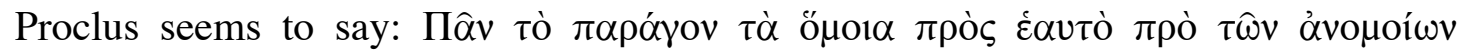

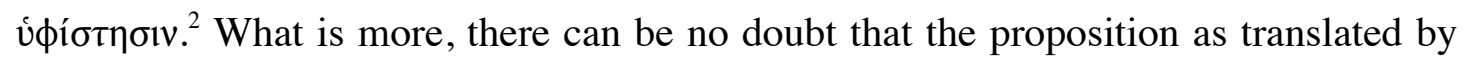
E.R. Dodds expresses ideas that agree with Proclus' system: productive causes typically produce certain effects directly, and other effects indirectly, more precisely through the products that originated first. Moreover, all procession from a cause is

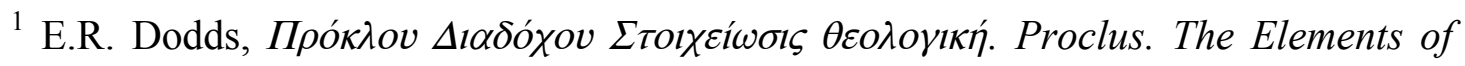
Theology. A Revised Text with Translation, Introduction and Commentary (Oxford, $\left.1963^{2}\right), 33$.

${ }^{2}$ ET 28, p. 32, lines 10-11 Dodds. The sentence is repeated, with slight variations, at p. 32 , line 34 - p. 34 , line 2 , and in the proof for proposition 29 , p. 34, line 5-6. 
accomplished through likeness, but the first products have a greater resemblance to the cause than further products generated by these first products. 'First' should of course not be understood as 'chronologically first', since most of the higher realities with which the Elements of theology are concerned transcend time, and so do their activities. The priority in Proclus' doctrine of procession is therefore ontological and causal: the existence and generation of the second products presuppose that of the first. Only for the things brought into existence by souls and nature could there be a chronological priority in addition to the ontological and causal priority. In proposition 28 , the idea of priority would be expressed by the preposition $\pi \rho$ ó. However, priority relations between products is not what the proposition is about, as I shall argue. On my reading, proposition 28 states that productive causes produce like effects rather than unlike effects, which amounts to the claim that they do not produce unlike effects. I should mention the possibility that E.R. Dodds when translating the preposition as 'before' may have intended it to have the value of 'rather than' - a perfectly acceptable usage of the preposition, especially in older English. ${ }^{4}$ This was, however, not how he was understood by later scholars of Proclus.

Concerning the point that I contest, other translations do not significantly differ from E.R. Dodds's. ${ }^{5}$ Moreover, all scholars, to my knowledge, have understood the

${ }^{3}$ See, e.g., ET 30 (procession through likeness); 36 (on the decreasing likeness of things proceeding from the causes); and 38 (for the idea that products can have many causes: not only their direct causes, but also the causes of their causes).

${ }^{4}$ L. Brown (ed.), The New Shorter Oxford English Dictionary on Historical Principles (Oxford, 1993), 1.205, s.v. 'before', B, III, 10.

${ }^{5}$ J. Trouillard, Proclos. Éléments de théologie (Bibliothèque philosophique) (Paris, 1965), 80: 'Tout producteur fait subsister des êtres semblables à lui-même avant d'en 
proposition accordingly. ${ }^{6}$ That is also true for the Byzantine bishop Nicholas of Methone who wrote a critique of the Elements of theology. In his treatment of susciter de dissemblables.' E. Di Stefano, Proclo. Elementi di teologia (Symbolon, 12) (Firenze, 1994), 103: 'Ogni produttore fa sussistere enti simili a se stesso prima dei dissimili.'; E. Sonderegger, Proklos. Grundkurs über Einheit. Grundzüge der neuplatonischen Welt. Text, Übersetzung, Kommentar (Sankt Augustin, 2004), 61: 'Jedes Hervorbringende stellt eher das ihm gegenüber Ähnliche auf als das Unähnliche.' Sonderegger's translation is the only one that can be understood as giving the required sense. His commentary, however, shows that he understands the text in line with the traditional interpretation, for there he refers to the proposition as stating that production proceeds through intermediaries, related to each other by degrees of similarity. Cf. ibid., at 220: 'Das Erzeugen geht über Vermittlungen, die zueinander das Verhältnis von Ähnlichkeitsstufen haben (§ 28).' As I argue, this is not what proposition 28 states, nor can it be inferred directly from the proof.

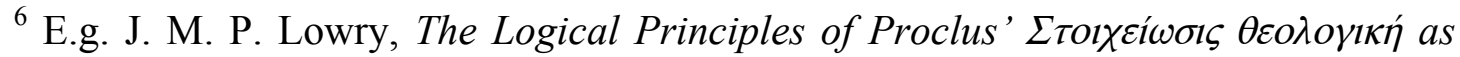
Systematic Ground of the Cosmos (Elementa. Schriften zur Philosophie und ihrer Problemgeschichte) (Amsterdam, 1980), 56; C. Steel, 'Proclus et Aristote sur la causalité efficiente de l'intellect divin', in: J. Pépin and H. D. Saffrey (edd.), Proclus, lecteur et interprète des anciens. Actes du colloque international du CNRS, Paris (2-4 octobre 1985) (Paris, 1987), 218, with n. 26; L. Siorvanes, Proclus: Neo-Platonic Philosophy and Science (Edinburgh, 1996), 58. W. Beierwaltes uses prop. 28 to make a point that agrees with how I understand the proposition, but in order to do so cites a part of the proof rather than the proposition itself: cf. Proklos: Grundzüge seiner Metaphysik (Philosophische Abhandlungen, 24) (Frankfurt am Main, 1965), 132, with n. 12 . 
proposition 28 he attacks the view according to which the (first) cause is more superior to some of its products than to others, an idea he supposes to be implied by the proposition. ${ }^{7}$ As I understand proposition 28, however, Proclus here makes no distinction between types of effects, neither in terms of hierarchy nor with respect to varying degrees of likeness to their cause(s).

Why should we doubt the accurateness of our translations and the correctness of an interpretation that seems obvious? Well, because another translation - one that equally agrees with Proclus' idiom - corresponds to that which is demonstrated in the ensuing proof, whereas the traditional translation does not. In order to obtain the required sense, we have to understand the preposition $\pi \rho$ ó not as referring to any sequence or order, but as having the value 'rather than', 'instead of'. The proposition then says that every cause brings into existence things like ${ }^{8}$ itself, and not things unlike itself. In other words: on my reading, proposition 28 does not state that $\mathrm{A}$ brings into existence first $\mathrm{B}$ and then $\mathrm{C}$ (presumably through $\mathrm{B}$ ), but rather that $\mathrm{A}$ brings into existence $\mathrm{B}$ rather than $\mathrm{C}$, given that $\mathrm{B}$ is more similar to $\mathrm{A}$ than $\mathrm{C}$. The main reason for reading the proof in the manner that I suggest lies in the demonstration that Proclus offer in support of the proposition. Since Proclus intends his Elements of Theology to be based on rigorous argument, the reader is entitled to

\footnotetext{
${ }^{7}$ Nicholas of Methone, Ref. 28, p. 38,8; 36,26-32 Angelou.

${ }^{8}$ L. P. Gerson objects against the use of the term 'likeness' as a translation of the

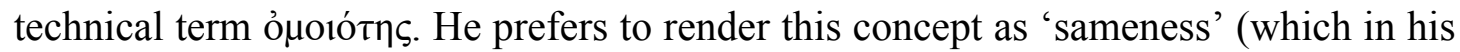
usage does not amount to 'identity'), but that usage has so far not met with broad acceptance. Cf. L. P. Gerson, 'Imagery and Demiurgic Activity in Plato's Timaeus', JNStud 4 (1996), 35-6, n. 4; 'Plato on Identity, Sameness, and Difference', RMeta 58 (2004), 305-32.
} 
expect that the demonstrans at least corresponds to the demonstrandum. The proof goes as follows: the producer is necessarily superior to the product, hence producer and product can neither be the same nor of equal power. They are therefore distinct from each other. This leaves two possibilities: either they are totally distinct, or they are both united and distinguished. But they cannot be totally different, for if they were, the product would not be participating in the producing cause. But there has to be such participation (this we already know from the preceding propositions). Hence producer and product are both united and distinguished. Next Proclus establishes which of the two - unity and difference -, if any, dominates. There are three possibilities to be considered. If producer and product are united and distinguished to the same degree, the product participates and does not participate in the producer to the same degree, and derives its essence and does not derive its essence from it to the same degree. Quod non. If producer and product are more distinct than they are united, they would be alien to one another. This is equally impossible. Thus the first two options are ruled out, on the basis of additional assumptions that we need not discuss here. The only remaining possibility is that producer and product are more united than they are distinct. This is confirmed by their kinship and sympathy (the disposition to be co-affected, that is) and by the desire of the product for the producing cause. The final premise of the argument consists in the claim that what is more united (than distinct) is more like than unlike. This leads directly to the conclusion, characteristically introduced by the particle ${ }^{\alpha} \alpha \alpha$, (p. 32, line 34 - p. 34, line 2): 'every productive cause therefore brings into existence like things rather than

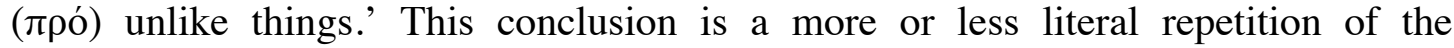
proposition itself. 
To understand the preposition $\pi \rho$ ó literally as 'before' does not make sense in the light of the preceding argument: Proclus has merely argued that causes produce effects that are like themselves, or more precisely: that are more like than unlike themselves. Nowhere has he mentioned secondary effects that are 'more unlike than like' the cause, and that are produced afterwards. The argument does not distinguish different types of effects, and does not entail this distinction either. It is true that its wording suggests that there are things that are more unlike than like a given cause, but of those, or rather of things that are more distinct than united to that cause, Proclus has denied that they are the products of that cause. We should therefore understand the conclusion of the argument - and hence also the proposition, which it merely repeats - as saying that productive causes produce things like them, and not things unlike them. The mention of unlike things distracts from the core of Proclus' claim, but can be explained by the fact that Proclus makes a shift from the phrase '(things)

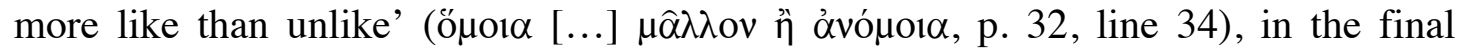
premise of the argument, to 'like things rather than unlike things', in the conclusion (p. 34, line 1).

The final premise of the argument (p. 32, lines 33-4) makes a simple comparison between two classes of things, stating that the degree of their being unified to one another correlates with their being similar: 'to be more unified than not' amounts to 'to be more like than unlike'. One can understand, from the preceding argument, that Proclus is comparing causes with effects, but actually the principle asserted in this premise, as I understand it, is a general one: it holds for all things that are more unified with other things than distinct from them. ${ }^{9}$ This general principle is meant to

\footnotetext{
${ }^{9}$ Hence E.R. Dodds's (n. 1., at 217) gloss, 'i.e. their immediate priors, to which they approach nearest', is somewhat misleading.
} 
be applied, implicitly, to the case of causes and effects. Be that as it may, the comparison is between just two classes of things. This notwithstanding, Proclus by implication refers to still other things, as he specifies that the similarity is to 'those things with which they are most $\left(\mu \alpha \lambda_{1} \sigma \tau \alpha\right)^{10}$ unified.' This suggests the existence of things that are less unified with them: when $\mathrm{X}$ is said to be 'most unified with $\mathrm{Y}^{\text {', the }}$ expression used suggests that there is a $\mathrm{Z}$ so that $\mathrm{X}$ is less unified with $\mathrm{Z}$ than it is with $\mathrm{Y}$. This is what may have given the idea to some interpreters that Proclus is comparing proximate and remote effects. The reference to other things is merely implicit, however, and nothing suggests that these are remote products of the same cause. Yet this peculiarity of the text softens the transition to the conclusion of the argument if one already thinks that this concerns a distinction between proximate and remote effects. It does not, however, provide argumentative justification for such a conclusion. Since Proclus' style of argumentation is relatively rigorous, it is unlikely that he would have allowed such a big jump in the argument.

A further, albeit weak, confirmation of my reading can be found in the proof for proposition 29, which invokes proposition 28 (ET 29, p. 34, line 5). Proclus uses the claim that 'the producing cause brings into existence like things prior to/rather than unlike things' (our proposition 28) to argue that likeness is the principle of generation. The relevance of the claim used as support for the new proposition is more obvious, I think, when it is understood simply as the idea that products are like the producing causes, rather than the premise that like products are produced before unlike products.

\footnotetext{
${ }^{10}$ E.R. Dodds (n. 1., at 217) argues that $\mu \alpha \dot{\lambda} \lambda ı \tau \alpha$ is to be preferred to the varia lectio $\mu \hat{\alpha} \lambda \lambda$ ov, as a corruption is more likely to have occurred from the latter to the former than vice versa.
} 
If I am right, the doctrine according to which causes produce also remote effects that are less like themselves than the primary effects is neither stated nor derivable from proposition 28. But is it at least reconcilable with it? The answer is positive. ${ }^{11}$ Productive causation and hence also procession do not only involve likeness or sameness, but also difference, as Proclus makes clear in the first lines of the proof (28, p. 32, lines 12-15). Hence, if the first products (B) of a cause A produce other things in turn (C), the latter will be less like the original cause. They will still be like A, only less so. They will be 'more unlike than like it', to turn around an expression from $\mathrm{p}$. 32, line 34. Moreover, Proclus is committed to the view that if A produces B and B produces $\mathrm{C}, \mathrm{A}$ is a cause of $\mathrm{C}$, too. For in that case $\mathrm{A}$ can be said to produce $\mathrm{C}$ through ( $\delta 1 \alpha$ ) B. The doctrinal justification for the claim consists in the idea that B

${ }^{11}$ This is also why prop. 55 does not constitute counter-evidence to my interpretation of prop. 28. Proclus appears to appeal to prop. 28 when he claims that 'before things that are wholly unlike' the first term of any series is succeeded by 'things that are more like than unlike' (ET 55, p. 52, lines 17-19; in the same lines he also quotes prop. 29). In the lines quoted, the preposition 'before' indeed has its literal meaning: A is succeeded first by B, which is 'more like than unlike' (compare ET 28, p. 32, line 34), and then by C, which is 'wholly unlike it.' Strictly speaking, however, prop. 28 can only be invoked for the claim that $\mathrm{A}$ is succeeded by $\mathrm{B}$, being 'more like than unlike.' Still, the idea that B is in turn followed by C, which is less like A than B, can be derived from the larger context: (1) the mention of things 'more like than unlike' suggests that there are also things that are 'more unlike than like'; (2) The term

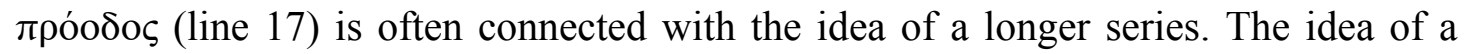
serial succession of more than two terms had been made explicit in prop. 36-8. 
transmits that which it has received from A to C. ${ }^{12}$ As a result, likeness is preserved through the entire causal chain, which is why even the lowest things contain a trace of the first cause: they all have unity and goodness.

Can the Greek preposition $\pi \rho o ́$, almost like its Latin twin, have the semantic value required by the argument? The answer is yes. LSJ cites several cases, from pre-koinê Greek, in which the preposition expresses 'preference'. ${ }^{13}$ This usage of the preposition belongs to the idiom of Plato, with which Proclus was very familiar. ${ }^{14}$ More

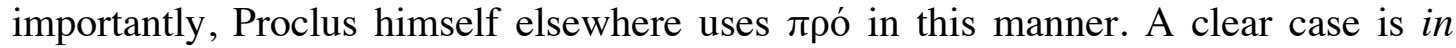
Remp. 2.63.27-8. Proclus is explaining that the guardians of Plato's state protect harmonic proportions in the sublunary world, especially when it comes to marriages.

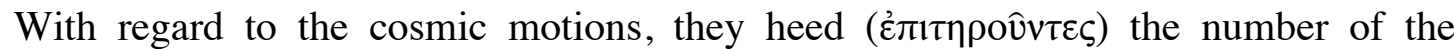
superior harmony rather than ( $\pi \rho$ ó) that of the inferior harmony. Obviously, the meaning is not that they first safeguard the superior harmony, and afterwards heed the inferior harmony. They rather seek to establish the superior harmony without seeking to realise a harmony that would be less good (unless, maybe, they fail to accomplish their first goal). The preposition $\pi \rho$ ó here expresses a preference. Whereas human guardians may not always be able to realise their preference, and are eventually forced to resort to the second-best option, this is not the case with 'metaphysical' or

${ }^{12}$ Cf. A. C. Lloyd, The Anatomy of Neoplatonism (Oxford, 1990), 104-7; R. Chlup, Proclus: An Introduction (Cambridge, 2012), 83-6.

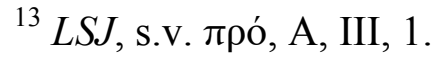

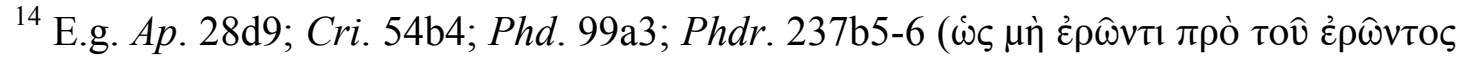

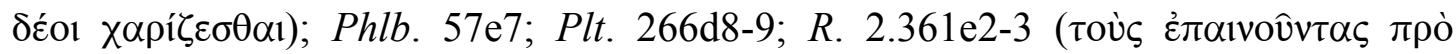

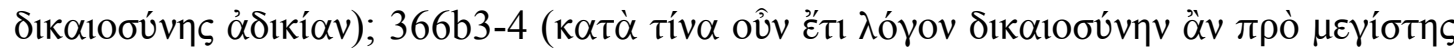

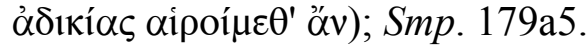


'theological' causation: divine causes invariably produce the best possible effects. This explains why ' $\mathrm{B}$ rather than $\mathrm{C}$ ' is in their case equivalent to ' $\mathrm{B}$, and not $\mathrm{C}$ '. That is what is stated by proposition $28 .{ }^{15}$

${ }^{15}$ This interpretation was developed by me during one of the meetings of a seminar organised by Gwenaëlle Aubry (UPR 76), Luc Brisson (UPR 76), Philippe Hoffmann (EPHE, LEM), Laurent Lavaud (Paris I), and Pieter d'Hoine (Leuven). The participants meet on a monthly basis, mostly in Paris but also in Leuven. It is our aim to produce a new annotated translation of the Elements of theology. 